\title{
La sociología en la educación secundaria en Brasil (1890-1971)
}

Recepción: 26/06/2020 | Revisión: 19/10/2020 | Aceptación: 03/12/2020 | Preprint: 07/01/2021 | Publicación: 01/03/2022

\author{
Amurabi OLIVEIRA \\ Universidad Federal de Santa Catarina, Brasil \\ amurabi1986@gmail.com \\ http://orcid.org/oooo-0002-7856-1196
}

\begin{abstract}
Resumen: La enseñanza de la Sociología en la educación secundaria brasileña comenzó a fines del siglo XIX, expandiéndose en el contexto de las reformas educativas que tuvieron lugar en las décadas de 1920 y 1930, integrando el campo más amplio de las ciencias sociales enseñadas en la escuela. Las reformas educativas llevadas a cabo en las siguientes décadas cambiaron el estado de esta asignatura en el currículo escolar, lo que tuvo implicaciones directas para la posibilidad de desarrollar una didáctica de la sociología en Brasil. En este artículo presentamos brevemente la historia de la sociología en la educación secundaria en Brasil entre finales del siglo XIX y la década de 1970, a través de una revisión de la literatura y de la legislación educativa, con el objetivo de contribuir al desarrollo de los fundamentos de una didáctica de la sociología en Brasil. Se concluye que, incluso en los momentos en que esta asignatura estaba ausente del plan de estudios de la escuela, el conocimiento sociológico continuó estando presente a través de otras asignaturas, impartidas por egresados del profesorado en ciencias sociales.
\end{abstract}

Palabras clave: enseñanza de sociología; historia de la sociología; educación brasileña; didáctica de la sociología; didáctica de las ciencias sociales.

\section{SOCIOLOGY IN SECONDARY EDUCATION IN BRAZIL (1890-1971)}

Abstract: The teaching of Sociology in Brazilian secondary education began in the late nineteenth century, expanding in the context of educational reforms that took place in the 1920s and 1930s, integrating the broader field of social sciences taught at school. The educational reforms carried out in the following decades changed the status of this discipline in the school curriculum, which had direct implications for the possibility of developing a didactic of sociology in Brazil. In this article we briefly present the history of sociology in secondary education in Brazil from the end of the 19th century until the 1970s, through literature and educational legislation reviews, with the aim of contributing to the development of the foundations of the didactics of sociology in Brazil. It is concluded that, even when this discipline was absent from the school curriculum, the sociological knowledge continued to be present through other disciplines, taught by graduates of teacher training courses in social sciences.

Keywords: teaching of sociology; history of sociology; Brazilian education; didactics of sociology; didactics of social sciences. 


\section{LA SOCIOLOGIA A L'EDUCACIÓ SECUNDÀRIA AL BRASIL (1890-1971)}

Resum: Al Brasil, l'ensenyament de la Sociologia en l'educació secundària va començar a finals del segle XIX, expandint-se en el context de les reformes educatives que van tenir lloc entre les dècades del 1920 i el 1930, integrant el camp més ampli de les ciències socials que s'ensenyen a l'escola. Les reformes educatives dutes a terme en les següents dècades van canviar l'estat d'aquesta assignatura en el currículum escolar. Això va tenir implicacions directes per a la possibilitat de desenvolupar una didàctica de la sociologia al Brasil. En aquest article presentem breument la història de la sociologia a l'educació secundària al Brasil entre finals del segle XIX i la dècada de 1970, a través d'una revisió de la literatura i de la legislació educativa, amb l'objectiu de contribuir al desenvolupament dels fonaments d'una didàctica de la sociologia al Brasil. Es conclou que, fins i tot en els moments en què aquesta assignatura no estava inclosa al pla d'estudis de l'escola, el coneixement sociològic va seguir a través d'altres assignatures, impartides per egressats del professorat en ciències socials.

Paraules clau: ensenyament de sociologia; història de la sociologia; educació brasilera; didàctica de la sociologia; didàctica de les ciències socials.

\section{Introducción}

La comprensión de cuáles son las ciencias sociales que componen el currículo de la educación secundaria es objeto de continuas disputas, ya que estas asignaturas exponen las contradicciones y los enfrentamientos entre las distintas opiniones acerca de la sociedad (Evans, 2006). Comprender los procesos históricos de introducción y exclusión de una asignatura especifica es un movimiento relevante para desarrollar su didáctica, ya que nos permite percibir sus principales retos en la realidad escolar.

En Brasil, la asignatura Sociología es una de las ciencias sociales que se enseñan en la escuela secundaria. Aunque su reintroducción en el currículo escolar se produjo a nivel nacional en 2008, cuando se convirtió en una asignatura obligatoria para todos los años de la educación secundaria, la sociología ya estaba introducida de manera relativamente heterogénea en los diferentes estados brasileños (Bodart et al., 2020). En 2017, en el contexto de la Reforma do Ensino Médio (Reforma de la Educación Secundaria), todas las materias escolares, con la excepción de las matemáticas y el idioma portugués, perdieron su obligatoriedad, por lo que son los estados los que eligen qué materias son obligatorias y qué contenido se debe enseñar. La sociología continúa siendo enseñada en el sistema educativo brasileño, a pesar de haber perdido espacio en los nuevos currículos de la educación secundaria en algunos estados.

En un período reciente, se ha ampliado la producción académica de artículos en Brasil sobre la enseñanza de la sociología en la educación secundaria (Oliveira y Melchioretto, 2020), así como el número de tesis de maestría y doctorado (Bodart y Cigales, 2017). Una parte importante de estos trabajos está dedicada a la historia de la enseñanza de la sociología, lo que demuestra la relevancia de este tema para los investigadores en la enseñanza de la sociología en Brasil. Bodart, Cigales y Brunetta (2019) señalan que si, por un lado, la discontinuidad de la presencia de la sociología en el currículo de la escuela ha generado dificultades para acumular debates específicos en este campo, por otro, existe un creciente interés en la comunidad de investigadores para comprender la historia de la asignatura. 
El objetivo de este artículo es contribuir al desarrollo de una didáctica de la sociología, revisando el primer momento de introducción de la sociología en los currículos de la educación secundaria, desde finales del siglo XIX hasta 1971, cuando se publicó una nueva ley nacional de educación, ya en el contexto de la dictadura militar. Como señalan Gómez-Carrasco, LópezFacal y Rodríguez-Medina (2019), el campo de la didáctica de las ciencias sociales ha desarrollado en los últimos años, pero la mayor parte de las investigaciones aún son concentradas en la la didáctica de la historia y la geografía, con pocos trabajos acerca de las demás ciencias sociales, de ese modo la investigación acerca de la historia de otras ciencias sociales en el currículum y de su didáctica puede contribuir a la ampliación de ese campo.

Llama la atención que la presencia de la sociología en la escuela en Brasil es un caso muy particular en la región. Trindade (2018) demuestra que en los países latinoamericanos las primeras cátedras de sociología han sido creadas en las universidades, algunas veces vinculadas a las Facultades de Derecho, pero en Brasil, la sociología ha desarrollado primero como una asignatura de la educación secundaria (Meucci, 2011; Oliveira, 2013). ${ }^{1}$

Para una mejor organización de nuestros argumentos, presentaremos la presencia de Sociología en el currículo escolar a través de dos períodos distintos: el primero desde finales del siglo XIX hasta Reforma Capanema (1942); el segundo, va hasta el período de la Reforma Passarinho (1971).

\section{Desde el siglo XIX hasta la Reforma Capanema (1942)}

En primer lugar, es importante reconocer que cuando nos referimos a la enseñanza de la Sociología en el siglo XIX, nos referimos a algo sustancialmente distinto de la comprensión que tenemos hoy de esta ciencia, en vista del grado de los avances en los debates teóricos y metodológicos. Además, la Sociología en la educación secundaria en ese momento incorporaba un conjunto de contenidos que luego serían reconocidas como parte de otros campos disciplinarios.

En trabajos sobre la historia de la enseñanza de la sociología en Brasil, se mencionan los pareceres de Rui Barbosa (1849-1923), que indicaban la introducción de la sociología en el currículo escolar. En este sentido es relevante aclarar algunos puntos: a) el parecer de 1882 presentado por Rui Barbosa se tituló «Parecer sobre la educación secundaria y superior», y tenía el propósito de justificar los proyectos de ley presentados a la Cámara de los Diputados, que fueron elaborados por su Comisión de Instrucción Pública, destinados a cerrar las brechas que quedaban en el decreto Leôncio de Carvalho (1947-1912); b) fue una reforma integral que tenía como objetivo modernizar la educación pública utilizando algunas instituciones como modelo para las demás, especialmente el Colégio Pedro II, indicando que el curso de bachillerato en la educación secundaria tendría una duración de seis años con las asignaturas: Portugués; Latín; Francés; Inglés; Alemán; Griego; Aritmética; Geometría; Física; Álgebra; Taquigrafía; Dibujar y Modelar Arte; Música; Aptitud; Geografía Antigua y Física; Historia Antigua y Media; Historia Moderna, Contemporánea y Brasileña; Zoología y Botánica; Contabilidad Comercial, Agrícola e Industrial; Historia de Ideas, Escuelas y Sistemas de Filosofía, Lógica, Moral; Elementos de Sociología y Derecho Constitucional;

\footnotetext{
${ }^{1}$ Hay otros dos aspectos singulares en la historia de la sociología brasileña en comparación con la sociología en la región, pero que no serán analizados en ese trabajo: a) en el período de la dictadura militar brasileña han sido creadas muchas carreras de pregrado y postgrado en ciencias sociales en Brasil, ya en países como Argentina y Uruguay las Facultades de Ciencias Sociales se cerraron en algunos períodos de la dictadura militar en eses países; b) la Sociología ha se convertido en una asignatura obligatoria en toda la educación secundaria en Brasil (2008-2017), una experiencia inédita en los países de la región, aunque los cambios políticos el los últimos años han creado nuevos retos para la enseñanza de las ciencias sociales (Oliveira, 2020).
} 
Mineralogía y Geología; Nociones de Análisis, Mecánica y sus Aplicaciones a Máquinas; Gramática Comparativa; Cosmografía; Agricultura; y Economía Política; c) también se hace referencia a la sociología en las nuevas disciplinas que se crearían para el curso de Derecho (Barbosa, 1942).

Por lo tanto, es necesario comprender los movimientos de introducción de la Sociología en la educación secundaria dentro de un conjunto más amplio de transformaciones por las que atraviesa Brasil. Además, esta era solo una de las propuestas existentes, había otras que indicaban otras formas de organización de la escuela.

También se debe tener en cuenta que la proximidad de la sociología con el derecho era muy fuerte en Brasil en ese momento (Cândido, 2006). En otros países latinoamericanos también ocurrió este tipo de relación entre sociología y derecho (Trindade, 2018), como en el caso de Uruguay, que hasta 2008 graduaba a sus profesores de Sociología a través del profesorado de Derecho, Educación Cívica y Sociología (Oliveira, 2019).

La Reforma Benjamin Constant, organizada por el Decreto no. 330, del 12 de abril de 1890, también indicó la introducción de la Sociología en la educación secundaria. Mediante este decreto, se propuso la siguiente organización del curso secundario:

\section{Primer año}

\section{$1 .{ }^{\circ}$ período}

Cátedra - Geometría general; Su complemento algebraico.

\section{$2 .{ }^{\circ}$ período}

Cátedra - Cálculo integral y diferencial (estudio completo). Nociones generales de cálculo de diferencias finitas.

Clase - Repetición de la cátedra del $10^{\circ}$ período.

Ambos períodos

Clase - Geometría descriptiva (estudio completo); obras gráficas correspondientes.

\section{Segundo año}

\section{0 período}

Cátedra - Mecánica general, precedida por el cálculo de variaciones; Sus aplicaciones a máquinas simples y balística en el vacío.

\section{2. ${ }^{\circ}$ período}

Cátedra - Astronomía, precedida por trigonometría esférica.

Clase - Repetición de la cátedra del $10^{\circ}$ período.

Ambos períodos

Clase - Teoría de sombras y perspectiva; dibujo correspondiente.

\section{Tercer año}

1.0 período

Cátedra - Física (estudio completo). Nociones de meteorología.

\section{$2 .{ }^{\circ}$ período}

Cátedra - Química (estudio completo).

Clase - Repetición de la cátedra del $10^{\circ}$ período.

Ambos períodos

Clase - Topografía (estudio completo).

\section{Cuarto año}

1.0 período

Cátedra - Biología, precedida por la síntesis histórica de las ciencias anteriores y seguida por la que le concierne.

\section{$2 .{ }^{\circ}$ período}

Cátedra - Sociología y moral.

Clase - Repetición de la cátedra del $1 .^{\circ}$ período.

\section{Ambos períodos}

Clase - Diseño de mapas topográficos; construcción y reducción de estas letras. 
La justificación para la introducción de esta disciplina estaba en las consideraciones preliminares hechas, que indicaban que las relaciones de dependencia entre las diferentes ciencias deben respetarse, de acuerdo con las leyes que regirían el espíritu humano. La organización de las asignaturas abarcaría desde las matemáticas hasta la sociología y la moral, con el objetivo de iluminar y aclarar el destino racional de todas las concepciones humanas.

En esta propuesta se percibe una clara influencia del positivismo en la concepción de la jerarquía de las ciencias y de la comprensión de su lugar en la formación intelectual de los estudiantes. En cualquier caso, esta reforma nunca se implementó (Machado, 1987).

Una de las primeras experiencias de introducir efectivamente la Sociología en el currículo escolar tuvo lugar en 1892 en Atheneu Sergipense, en Aracaju, a través de una asignatura llamada «sociología, moral, nociones de economía política y derecho de la patria», cuyos contenidos eran «poco sociológicos» (Alves y Costa, 2006), algo que también pasó en el Colégio Pedro II en 1925 (Guelfi, 2007).

Esta observación es relevante porque indica las dificultades de delimitar claramente los límites de la sociología con otras ciencias sociales en el currículo en ese momento. La aparición de cátedras con la denominación estricta de Sociología está vinculada a las Reformas Rocha Vaz en 1925, y Francisco Campos en 1931, que representa un hito importante para que pensemos en el proceso de institucionalización de la enseñanza de la Sociología en la educación secundaria (Silva, 2010).

La Reforma de Rocha Vaz fue implementada por el decreto número 16.782 del 13 de enero de 1925, estableciendo la siguiente organización disciplinaria para la educación secundaria: 1.0 año: 1) Portugués, 2) Aritmética, 3) Geografía general; 4) Inglés, 5) Francés, 6) Instrucción moral y cívica, 7) Dibujo; $2 .^{\circ}$ año: 1) Portugués, 2) Aritmética, 3) Geografía (corografía de Brasil), 4) Historia Universal, 5) Francés, 6) Inglés o Alemán, 7) Latín, 8) Dibujo; 3.0 año: 1) Portugués, 2) Historia Universal, 3) Francés, 4) Inglés o Alemán, 5) Latín, 6) Álgebra; 7) Dibujo; 4.0 año: 1) Portugués (Gramática Histórica), 2) Latín, 3) Geografía y Trigonometría, 4) Historia de Brasil, 5) Física, 6) Química, 7) Historia de lo Natural, 8) Dibujo; 5.0 año: 1) Portugués (nociones de literatura), 2) Cosmografía, 3) Latín, 4) Física, 5) - Química, 6) Historia Natural, 7) Filosofía, 8) Dibujo; $6.0^{\circ}$ año: 1) - Literatura Brasileña, 2) Literatura en Lengua Latina, 3) Latín, 4) Filosofía, 5) Sociología. Dentro de esta formación enciclopédica, la Sociología sería una de las asignaturas con menos horas, solo una cátedra, así como Alemán, Instrucción Moral y Cívica, y Cosmografía.

Con la Reforma de Francisco Campos - decreto no 19.890 del 18 de abril de 1931 - la educación secundaria se dividiría en educación primaria de cinco años y educación complementaria de dos años. En este escenario, la sociología comenzó a integrar los cursos complementarios que eran obligatorios para ingresar a la educación superior y consistían en las siguientes materias: Alemán o Inglés. Latín, Literatura, Geografía, Geofísica o Cosmografía, Historia de la Civilización, Matemáticas, Física, Química, Historia Natural, Biología General, Higiene, Psicología y Lógica, Sociología, Nociones de Economía y Estadística, Historia de la Filosofía y Dibujo.

La introducción de la Sociología en la educación secundaria en este momento se entendió, según la interpretación de Meucci (2011, p.57), «como uma área de conhecimento 
dedicada à renovação da vida intelectual, à substituição do ensaísmo jurídico e literário pelo realismo científico». Acerca del proceso de introducción de la Sociología en el currículo escolar Moraes (2011, p. 362) Ilama la atención sobre algunos aspectos que otros investigadores pasan por alto en este tema:

É necessário dizer que esse espraiamento do ensino de Sociologia ocorreu na ausência de cursos de formação de professores de Sociologia, sendo comum a presença de advogados, médicos e engenheiros para cobrir essa carência. É interessante também notar que essa Reforma (1925), que, entre outras providências, institui a obrigatoriedade do ensino de Sociologia na escola secundária de então - cursos preparatórios e complementares -, foi concebida durante o governo talvez mais autoritário da chamada República Velha, o de Arthur Bernardes.

Por lo tanto, este sería un proceso profundamente complejo y contradictorio, ya que no podemos olvidar el aspecto elitista que la educación secundaria representaba en ese momento, al que tenía acceso solamente una pequeña porción de la población brasileña.

También se destaca la relevancia de la enseñanza de la Sociología en las llamadas Escolas Normais (Escuelas Normales) ${ }^{2}$, también vinculada a una propuesta para modernizar los currículos de los cursos de formación de profesores. En el caso del estado de Pernambuco, Gilberto Freyre se convirtió en su primer profesor de sociología (1900-1987) aún en la década de 1920. Este sociólogo y antropólogo aún no había publicado su obra más conocida, CasaGrande y Senzala, pero tenía una sólida formación académica en ciencias sociales ${ }^{3}$.

Como las carreras de pregrado (licenciatura y profesorado) en Ciencias Sociales solo se crearon en Brasil a partir de la década de 1930, la primera generación de profesores de Sociología fue formada por intelectuales autodidactas en este campo. Estos datos fueron objeto de duras críticas por parte de autores como Guerreiro Ramos (1954, pp. 46-47):

nossos autores de compêndios não têm, salvo raríssimas exceções, uma experiência vivida dos problemas e assuntos de que tratam. Seus textos escolares não são propriamente fruto de meditação dos assuntos. Resultam, com frequência, de glosas, paralelos, pastiches e transcrições de obras estrangeiras. Julgo que essa deficiência da maioria de nossos livros escolares se explicam pelas próprias condições objetivas do País.

Os professores brasileiros de sociologia, em grande parte, têm exercido a cátedra por acaso. Ordinariamente, tem sido um fator aleatório em suas vidas o que os leva a ser professor de sociologia. Não se prepararam para tal. Aqui as cátedras de sociologia não surgiram para consagrar uma tradição militante de trabalho pedagógico, como é a regra em todos os países avançados. As cátedras aparecem de modo intempestivo e foram providas, inicialmente, mais ou menos, por pessoas que, no momento, ou eram diletantes, quanto muito; ou desconheciam completamente os estudos de sociologia. Muitos foram estudar a matéria depois de nomeados professores; durante algum tempo, ao menos, foram nos seus postos verdadeiros simuladores, aparentando um saber que realmente não possuíam.

\footnotetext{
${ }^{\mathbf{2}}$ Estas instituciones se introdujeron en Brasil en la primera mitad del siglo XIX y se convirtieron en el espacio principal para la formación de profesores en Brasil en ese momento (Saviani, 2011).

${ }^{3}$ Gilberto Freyre se graduó en Ciencias Políticas y Sociales por la Universidad de Baylor en Texas y obtuvo una maestría en Historia Social por la Universidad de Columbia en Nueva York. Durante su maestría, tomó cursos en los departamentos de Sociología y Antropología
} 
Estas críticas son relevantes para que no caigamos en anacronismos al analizar la historia de la Sociología en la escuela. Como Meucci (2015) indica acertadamente, la Sociología que existió en ese período y la que regresa a los currículos en las últimas décadas del siglo XX son sustancialmente distintas.

De este modo, destacamos el carácter complejo presente en el proceso de introducción de la enseñanza de la Sociología, especialmente al considerar las interpretaciones y explicaciones post factum desarrolladas por investigadores que tienden a interpretar las ausencias y presencias de la sociología en el currículo escolar como un fenómeno vinculado al carácter ideológico y crítico de la asignatura, dejando de lado el carácter conservador que puede la sociología asumir en términos teóricos.

No negamos la posibilidad de exclusiones e inclusiones de asignaturas escolares debido a cambios políticos y sociales, ya que este fenómeno ocurre, sin embargo, estos cambios no son mecánicos. Como señala Moraes (2011), hubo períodos democráticos en los que la Sociología fue excluida del currículo y momentos antidemocráticos en los que estuvo presente en la educación secundaria.

En este sentido, son aclarativas las instrucciones encontradas en el libro de texto Sociologia: Compendio Escolar para o Curso Gymnasial, escrito por A Lorton, publicado en 1926, que posiblemente ha sido uno de los primeros libros de sociología en Brasil para escuelas, (Oliveira, 2013). El libro fue editado por Livraria Alves, vinculada a la congregación marista en la primera parte del libro encontramos "A Modo de Preácio", que contiene la "Voz de los Obispos". Esa primera parte especifica 31 reglas, 26 generales y cinco particulares, algunas de ellas nos llamaron la atención:

II - Como Deus a estabeleceu, consta, a sociedade humana de elementos desiguaes. Deve-se reprovar, porque é contrário á natureza, qualquer projecto de nivelamento, absurdo e inexequivel, das condições humanas. (Lorton, 1926, p. 4);

XXI - No ensino desta disciplina, será preciso usar da maxima cordura, tratando todos os pontos com grande espirito de pacificação, de moderação e muito juizo. Evitar, com excepcional cuidado, tudo quanto possa favorecer a utopia socialista, como sejam certas ideias mais ou menos liberaes, ou o emprego sempre despropositado da terminologia em voga entre os adeptos da luta das classes. (Lorton, 1926, p. 13).

Nos damos cuenta de que lejos de constituir una discusión basada en el pensamiento crítico, la sociología también puede presentarse como una asignatura conservadora, preocupada por afirmar una visión armoniosa de la realidad social, y con el proceso de construir una cierta concepción del hombre, como podemos ver en una más de las reglas presentes en este libro:

XXIX - Nas sociedades de mocinhos em idade escolar não convem chamar a attenção dos meninos para problemas socieaes destoantes da sua condição. E ninguem pense que trabalhou debalde só porque não formou mentalidades precipuamente syndicalistas. O fim dessas reuniões é criar homens catholicos, de convicções arraigadas, christãos firmes e solidos. Isto, pelo conhecimento mais aprofundado das verdades religiosas, por uma conducta sempre honesta, pura e illibada, e frequentação assidua dos sacramentos, pela penetração lenta de todas as virtudes naturaes e sobrenaturaes. (Lorton, 1926, p. 12-13). 
Es interesante notar que este trabajo publicado originalmente en 1923 en Francia pronto recibió una traducción en Brasil, que también incluyó el cambio de su título Notions de Sociologie para otro en el cual se destaca su utilización en la escuela. Este libro fue revisado por R. Laubier en la reconocida revista L'Année sociologique aún en 1923, y el autor indicó que este trabajo tiene la intención de presentarnos una moral inspirada directamente por la doctrina católica y apoyada en una frágil sociología (Laubier, 1923, p. 210).

Observar las instrucciones para la enseñanza de la sociología desde ese libro de texto ayuda a aclarar las contradicciones en la enseñanza de la sociología en Brasil en ese período, una vez que esa era una de las visiones que estaban en disputa en ese campo. Es importante tener en cuenta aún que:

\begin{abstract}
Se debe tener en cuenta que los libros de texto no son creaciones con contenidos aleatorios propuestos por sus autores, sino que su elaboración tiene una relación con los marcos normativos que rigen, en general, los sistemas educativos. En este sentido, reflejan de una forma $u$ otra, los objetivos educativos de determinados momentos históricos en realidades concretas. Son así, productos materiales que permiten indagar en las construcciones simbólicas y discursivas sobre la educación y, en nuestro caso, las ciencias sociales. (Sáez-Rosenkranz y Prats Cuevas, 2018, p. 3-4).
\end{abstract}

En el período en que se publicó este libro en Brasil, destaca el choque entre intelectuales católicos y liberales, que en el campo de la sociología se fundamenta en la producción de manuales para esa asignatura, dirigidos a escuelas de educación básica, escuelas normales y cursos de educación superior. Muchos de estos libros fueron escritos por autores desconocidos para el mundo académico, así como por intelectuales de renombre, como Afro Amaral Fontoura (1912-1987), Alceu Amoroso Lima (1893-1983), Delgado de Carvalho (1884-1980), Carneiro Leão (1887-1966), Fernando Azevedo (1884-1974), Gilberto Freyre. La mayor parte de eses autores presentan una formación ecléctica autodidacta y con un fuerte vínculo con el Estado.

Las tensiones que existieron en la enseñanza de la Sociología en el período reflejaron, sobre todo, diferentes concepciones de la nación, basadas en un lado, en un mesianismo religioso, representado por el pensamiento educativo católico, por el otro, en una especie de mesianismo científico, representado por el movimiento de la Escuela Nueva ${ }^{4}$ (Cury, 1988).

Es innegable que para el Movimiento Escuela Nueva la sociología era una herramienta teórica importante para la renovación intelectual, que podría garantizar la cientificidad al currículo escolar. Fernando de Azevedo, un de los principales intelectuales de ese movimiento, era considerado como el gran heredero intelectual de Durkheim en el campo de sociología de la educación en Brasil (Bontempi Júnior, 2011), dialogando aún con el trabajo de John Dewey (1859-1852). Es dentro de este marco teórico que la sociología comienza a ocupar un lugar destacado en los cursos de formación de profesores (Escuelas normales), habiéndose

\footnotetext{
${ }^{4}$ Para un mejor análisis del debate promovido por la Escuela Nueva, especialmente después de la publicación del Manifiesto de los Pioneros de la Educación en 1932, ver los trabajos de Nagle (1976), Cury (1988), Xavier (2002), Saviani (2009).
} 
introducido esa asignatura en un momento de revisión de los currículos de eses cursos, lo que refleja los cambios que la educación había experimentado en la primera mitad del siglo 20 (Nagle, 1976).

Lo que podemos ver en este escenario es que la introducción de la Sociología tuvo lugar en medio de un proceso contradictorio, ya que, por un lado, su consolidación se produjo durante la Reforma de Francisco Campos en 1931, y su retirada durante la Reforma de Capanema, en 1942, ambas en el gobierno del presidente Getúlio Vargas (1882-1954)5 ${ }^{5}$ que permaneció en el poder entre 1930 y 1945, y más tarde entre 1951 y 1954.

\title{
2. Desde la Reforma Capanema hasta la Reforma Passarinho (1971)
}

En la literatura que trata sobre la enseñanza de la Sociología, la Reforma de Capanema es referida como la reforma que ha interrumpido la continuidad de la sociología en los planes de estudio escolares, pero se ha observado poco la proximidad que existe entre las reformas responsables por la introducción y la retirada de la sociología del currículo de la educación secundaria. En este sentido, son relevantes las afirmaciones de Saviani (2011, p.270) sobre este período son:

\begin{abstract}
A característica mais saliente das reformas educacionais empreendidas por Campos e Capanema traz a marca do pacto com a Igreja Católica costurado por Francisco Campos no início da década de 1930. Por esse pacto Vargas, apesar de sua origem castilhista, se dispôs a apoiar a inclusão das teses católicas na Constituição de 1934, recebendo em troca o apoio político da Igreja. Aliás, em seu berço de origem, o Rio Grande do Sul, o castilhismo no poder já havia estreitado relações com a Igreja, como o evidenciam os trabalhos de Jaime Giolo (1997) e Elomar Tambara (1995). do referido pacto decorreu uma forte influência da liderança católica, em particular de Alceu Amoroso Lima, na formulação da política educacional e especialmente na composição do quadro de pessoal. Além da função de aconselhamento, as cartas de Alceu dirigidas a autoridades governamentais, em especial a Campos e Capanema, revelam sua influência na indicação de determinados nomes e no veto a outros para o exercício de cargos públicos, em especial no magistério. Essa circunstância, ao aproximar a Igreja do aparelho de Estado, diluiu as críticas dos católicos ao chamado monopólio estatal do ensino, de que eram acusados os renovadores. Com efeito, pelo acordo estabelecido, a Igreja acabou, em termos práticos, admitindo a presença ativa do Estado na educação, muito além do que Ihe era permitido no campo doutrinário.
\end{abstract}

Lo que podemos concluir, de esta incursión, es que afirmar que la Sociología simplemente habría sido eliminada del currículo escolar en gobiernos autoritarios es una simplificación con un fuerte anacronismo. En este tipo de análisis, se interpreta la sociología escolar de las décadas de 1920, 1930 y 1940 a través de la figuración específica de la sociología académica de la década de 1950. Acerca de la sociología brasileña en la década de 1950, Villas Bôas (2006, p. 80) afirma que:

\footnotetext{
${ }^{\mathbf{5}}$ Con esto, no queremos ocultar aquí las diferencias sustanciales que existieron en los dos contextos políticos diferentes, ya que, sin lugar a dudas, en una sola década hubo un cambio sustancial en el escenario político y social en Brasil, con énfasis en el advenimiento de la dictadura civil en 1937 (el Estado Nuevo).
} 
os sociólogos reivindicam o lugar de intelectuais/cientistas, grupo treinado especificamente para o exercício da ciência como profissão. Enquanto cientistas profissionais, incluem-se privilegiadamente entre os agentes das mudanças sociais. Há um nítido entrelaçamento do fazer ciência e fazer história.

En este sentido, las preguntas planteadas por Moraes (2011) parecen plausibles al interpretar el proceso de exclusión de la Sociología en 1942 del currículo escolar durante la Reforma de Capanema. De acuerdo con el autor:

entendemos que a exclusão da Sociologia do currículo prende-se menos a preconceitos ideológicos e mais à indefinição do papel dessa disciplina no contexto de uma formação que se definia mais orgânica, resultado do estabelecimento de uma burocracia mais técnica e mais exigente ou convicta em relação à concepção de educação. De certa forma, pode-se dizer que os defensores da Sociologia não conseguiram convencer essa burocracia educacional quanto à necessidade de sua presença nos currículos. (Moraes, 2011, p. 65).

Nunca es demasiado recordar que la Reforma Capanema, lejos de tener como objeto específico la enseñanza de la sociología, se centró en llevar a cabo un conjunto de reformas que tenían un carácter centralista, burocrático y dualista, que separaba la educación secundaria, dirigida a las élites, de la educación profesional (Saviani, 2011). En este proceso, los cursos complementarios (bachillerato), donde se enseñaba Sociología, se extinguieron, organizando la educación secundaria en dos ciclos: secundaria y preparatoria. Por lo tanto, la extinción de la Sociología tuvo lugar en medio de este conjunto de reformas, incluida la de la educación secundaria ${ }^{6}$. Soares $(2009$, p. 79) al referirse a esta reforma señala que:

\begin{abstract}
Um dos objetivos da Reforma Capanema foi desatrelar formalmente o ensino secundário do ensino superior, dando-Ihe um projeto pedagógico próprio. Por isso, a principal mudança nela estabelecida foi a extinção dos cursos complementares que visavam a preparação para as carreiras superiores de direito, medicina e engenharia. Uma das conseqüências do fim desses cursos foi a eliminação da disciplina Sociologia, que na perspectiva apresentada pela Reforma Capanema, desempenhava uma função mais preparatória do que formativa. Nessa Reforma então, a Sociologia deixa de ser obrigatória e alguns dos seus conteúdos passam a integrar a proposta curricular de Filosofia no $3^{\circ}$ ano do curso clássico.
\end{abstract}

Con esta Reforma, el momento de estabilidad experimentado por la Sociología en los currículos escolares termina, marcado, abiertamente, por una profunda falta de definición de su papel. Vale la pena señalar el hecho de que, según Schwartzman, Bomeny y Costa (2000), la reforma de la educación secundaria de 1942 se caracterizaría por la intención de consolidar la escuela secundaria como la principal institución educativa y, además, se esperaba que produjera una nueva elite para el país. Una élite católica, masculina, de formación clásica y disciplina militar. Esa reforma permaneció prácticamente sin cambios hasta la primera Ley de

${ }^{6}$ Las reformas conducidas por Capanema fueron conducidas por un total de ocho decretos-leyes: No. 4,048, del 22 de enero de 1942, que creó el SENAI; 4073, de 30 de enero de 1942, Ley Orgánica de Educación Industrial; No. 4,244, del 9 de abril de 1942, Ley Orgánica de Educación Secundaria; 6.141, del 28 de diciembre de 1943, Ley Orgánica de Educación Comercial; 8.529, del 2 de enero de 1946, Ley Orgánica de Educación Primaria; 8.530, del 2 de enero de 1946, Ley Orgánica de Educación Normal; 8.621, del 10 de enero de 1946, creó SENAC; nº 9.613, del 20 de agosto de 1946. Ley Orgánica de Educación Agrícola. 
Directrices y Bases de la Educación en 1961. Aún es importante decir que la Sociología siguió en el currículo de las escuelas normales (formación de profesores). Más que eso, debe considerarse que las categorías, teorías y conceptos sociológicos continuaron circulando en el espacio escolar a través de otras disciplinas.

Otro tema complejo que debe plantearse en esta discusión se refiere al hecho de que la desaparición de la sociología de los currículos escolares se produjo simultáneamente con el aumento de su institucionalización en la educación superior. Como indica el análisis de Liedke Filho (2005), en el período comprendido entre 1954 y 1976 hubo un aumento sustancial en los cursos de pregrado en el área, pasando de 11 a 83 cursos (licenciaturas y profesorados). Por lo tanto, debe considerarse que lo que estaba en marcha era una redirección de la Sociología en términos del campo de la enseñanza, y no simplemente su desaparición.

Otro paso significativo que impactó la enseñanza de la Sociología en Brasil fue la Reforma Passarinho en 1971, que a través de la nueva Ley Nacional de Educación (Ley Nº 5.692 del 11 de agosto de 1971) señaló la profesionalización obligatoria de los currículos de Segundo Grau (Educación secundaria), e indicó en su artículo 7 que "Será obrigatória a inclusão de Educação moral e Cívica, Educação Física, Educação Artística e Programas de Saúde nos currículos plenos dos estabelecimentos de $1^{\circ}$ e $2^{\circ}$ graus, observado quanto à primeira o disposto no Decreto Lei n. 369, de 12 de setembro de 1969".

Notablemente, hubo un tenor ideológico explícito en la enseñanza de tal asignatura, porque como se indica en el segundo artículo de ese decreto ley:

A Educação Moral e Cívica, apoiando-se nas tradições nacionais, tem como finalidade:

a) a defesa do princípio democrático, através da preservação do espírito religioso, da dignidade da pessoa humana e do amor à liberdade com responsabilidade, soba inspiração de Deus;

b) a preservação, o fortalecimento e a projeção dos valores espirituais e éticos da nacionalidade;

c) o fortalecimento da unidade nacional e do sentimento de solidariedade humana;

d) o culto à Pátria, aos seus símbolos, tradições, instituições e aos grandes vultos de sua história;

e) o aprimoramento do caráter, com apoio na moral, na dedicação à família e à comunidade;

f) a compreensão dos direitos e deveres dos brasileiros e o conhecimento da organização sócio-político-econômica do País;

g) o preparo do cidadão para o o exercício das atividades cívicas com fundamento na moral, no patriotismo e nação construtiva, visando ao bem comum;

h) o culto da obediência à Lei, da fidelidade ao trabalho e da integração na comunidade. 
También en el mismo período en el anexo del parecer número 853/71 de la Resolución número 8 del 1 de diciembre de 1971, hay una indicación de que el núcleo común de la educación primaria y secundaria está formado por las áreas de Comunicación y Expresión; Estudios sociales y; Ciencias. En el cómputo de los estudios sociales habría las asignaturas de historia, geografía y organización social y política de Brasil (OSPB). La educación moral y cívica, junto con la educación física, la educación artística, los programas de salud y la educación religiosa eran obligatorias para las escuelas, pero opcionales para los estudiantes.

Esta información también es relevante para aclarar el argumento que aparece recurrentemente en la literatura sobre enseñanza de Sociología, lo que indica la sustitución de la asignatura por la de OSPB, cuando en realidad existe una gran brecha de tiempo entre la retirada de la Sociología de los currículos y la inclusión de esas nuevas asignaturas. Además, la asignatura OSPB se creó en un período anterior a la dictadura militar, aunque se ha sido afectada en términos de la orientación ideológica de sus contenidos.

Recurrentemente, los cursos profesorado de ciencias sociales hasta los años de 1990 tenían una formación de práctica pedagógica en OSPB, lo que indica que posiblemente las categorías y conceptos sociológicos circulaban en las escuelas, incluso si no era a través de un espacio disciplinario. Los profesores que enseñaban OSPB han tenido una formación teórica en el campo de la sociología, así como en otras ciencias sociales, como antropología, ciencia política, historia y geografía.

Por lo tanto, debemos reconocer que la Sociología no tuvo un espacio disciplinario en el período, pero esto no es lo mismo que decir que no hubo circulación de conocimiento sociológico en las escuelas, especialmente teniendo en cuenta que parte de los profesores que enseñaban Estudios Sociales y OSPB eran graduados de títulos universitarios. en ciencias sociales.

\section{Consideraciones finales}

En este trabajo buscamos no solo presentar descriptivamente la historia de la Sociología en el currículo escolar dentro de un cierto período histórico (1890-1971), sino que también señalar una interpretación que nos permita percibir los movimientos de la sociología en la escuela. Destacamos que mismo cuando no hay una presencia disciplinaria de esa ciencia social en el currículo, eso no extingue la posibilidad de circulación de teorías y conceptos sociológicos.

También es digno de mención que la ausencia de sociología en la escuela ocurrió simultáneamente con una expansión significativa de las ciencias sociales en la educación superior en Brasil, especialmente si consideramos el último período analizado, comenzando en los años 1960/70. Después de la Reforma Universitaria de 1968, los estudios de posgrado aparecieron en Brasil en el modelo similar a lo que conocemos hoy, lo que resultó en un fuerte aumento de la investigación en esta área del conocimiento.

Aunque no fue el foco de este artículo, vale la pena señalar la presencia continua de la Sociología a través de las escuelas normales, aunque en el último período analizado la asignatura se ha disuelto en el área de Fundamentos de la Educación. 
Finalmente, entendemos que, a pesar de la relevancia de revisar la historia de la enseñanza de Sociología a nivel nacional, es necesario llevar a cabo un esfuerzo de investigación más centradas en las historias locales, en torno a la presencia de las ciencias sociales en la escuela. Eses son puntos fundamentales para desarrollar una didáctica de la sociología en Brasil.

\section{Agradecimientos}

Este artículo es resultado de mi periodo de investigación postdoctoral en la Universidad Autónoma de Barcelona con financiación de la beca CAPES PVE-Júnior, con la supervisión del profesor Antoni Santisteban, a quién agradezco por la recepción en su grupo de investigación (GREDICS).

\section{Referencias bibliográficas}

Alves, E. M. S. y Costa, P. R. S. M. (2006). Aspectos históricos da cadeira de Sociologia nos estudos secundários (1892-1925). Revista Brasileira de História da Educação, 6(12), 31-51. http://periodicos.uem.br/ojs/index.php/rbhe/article/view/38626

Barbosa, R. (1942). Obras completas. v. IX, t. 2. Ministério da Educação e Saúde.

Bodart, C. N., Azevedo, G. C. y Tavares, C. S. (2020). Ensino de Sociologia: processo de reintrodução no Ensino Médio brasileiro e os cursos de Ciências Sociais/Sociologia (1984-2008). Debates em Educação, 12(27), 214-235. http://dx.doi.org/10.28998/2175-6600.2020v12n27

Bodart, C. N. y Cigales, M. (2017). Ensino de sociologia no Brasil (1993-2015): um estado da arte na pós-graduação. Revista de Ciências Sociais, 48(2), 256-281. https://bit.ly/3jscgTh

Bodart, C. N., Cigales, M. y Brunetta, A. A. (2019). A pesquisa sobre a História do Ensino de Sociologia no Brasil. En H. Caruso y M. B. Santos (Coords.), Rumos da Sociologia na educação básica: Reformas, resistências e experiências de ensino (1.a ed., pp. 137-146). Cirkula.

Bontempi Junior, B. (2011). A presença visível e invisível de Durkheim na historiografia da educação brasileira. En L. M. Faria Filho (Ed.), Pensadores Sociais e História da Educação ( $1^{\mathrm{a}}$ ed., pp. 49-64). Autêntica.

Brasil. Fixa o núcleo comum para os currículos do ensino de $1^{\circ}$ e $2^{\circ}$ graus, definindo-lhe os objetivos e amplitude. Anexo ao parecer 853/71 da Resolução $n^{\circ} 8$ de $1^{\circ}$ de dezembro de 1971 (1971).

Brasil. Promulga o regulamento que reorganiza o ensino nas escolas do Exercito, Decreto ${ }^{0} 330$, de 12 de abril de 1890 (1890).

Brasil. Estabelece o concurso da União para a difusão do ensino primário, organiza o Departamento Nacional do Ensino, reforma o ensino secundário e o superior e dá outras providências, Decreto $\mathrm{n}^{0}$ 16.782-A de 13 de janeiro de 1925. Estabelece o concurso da União para a difusão do ensino primário, organiza o Departamento Nacional do Ensino, reforma o ensino secundário e o superior e dá outras providências (1925).

Brasil. Dispõe sobre a organização do ensino secundário, Decreto $\mathrm{n}^{0} 19.890$ de 18 de abril de 1931.

Brasil. Dispõe sobre a inclusão da Educação Moral e Cívica como disciplina obrigatória, nas escolas de todos os graus e modalidades, dos sistemas de ensino no País, e dá outras providências, Decreto Lei n. 369, de 12 de setembro de 1969.

Brasil. Fixa as Diretrizes e Bases da Educação Nacional, Lei no 4.024, de 20 de dezembro de 1961.

Brasil. Fixa diretrizes e bases para o ensino de $1^{\circ}$ e $2^{\circ}$ graus, e dá outras providências, Lei ${ }^{\circ} 5.692$, de 11 de agosto de 1971 (1971). 
Cândido, A. (2006). A sociologia no Brasil. Tempo Social, 18(1), 271-301. https://www.scielo.br/pdf/ts/v18n1/30018.pdf

Cury, C. R. J. (1988). Ideologia e Educação Brasileira: católicos e liberais. Cortez.

Evans, R. W. (2006). The social studies wars, Now and then. Social Education, 7o(5), 317-321. https://www.socialstudies.org/system/files/publications/articles/se_700506317.pdf

Gómez-Carrasco, C. J., López-Facal, R. y Rodríguez-Medina, J. (2019). La investigación en Didáctica de las Ciencias Sociales en revistas españolas de Ciencias de la Educación. Un análisis bibliométrico (2007-2017). Didáctica de las Ciencias Experimentales y Sociales, (37), 67-88. https://doi.org/10.7203/dces.37.14440

Guelfi, W. P. (2007). O movimento da sociologia como disciplina escolar entre 1925 e 1942: as reformas do secundário e os programas de ensino do Colégio Pedro II. Revista Mediações, 12(1), 11-30. http://www.uel.br/revistas/uel/index.php/mediacoes/article/view/3385

Guerreiro Ramos, A. (1954). Cartilha brasileira do aprendiz de sociólogo. Est. De Artes Gráficas C. Mendes Jr.

Laubier, R. (1923). Notions de Sociologie pour A. Lorton. L'Année Sociologique, 1, 208-210.

Liedke Filho, E. (2005). A Sociologia no Brasil: história, teorias e desafios. Sociologias, (14), 376-437. https://doi.org/10.1590/S1517-45222005000200014

Lorton, A. (1926). Sociologia: compendio escolar para o curso gymnasial. Livraria Alves.

Machado, C. de S. (1987). O ensino de sociologia na escola secundária: um levantamento preliminar. Revista da Faculdade de Educação, 13(1), 115-142.

Meucci, S. (2011). Institucionalização da sociologia no Brasil: primeiros manuais e cursos. Hucitec: Fapesp.

Meucci, S. (2015). Sociologia na educação básica no Brasil: um balanço da experiência remota e recente. Ciências Sociais UNISINOS, 51(3) 251-26o. https://doi.org/10.4013/csu.2015.51.3.02

Moraes, A. C. (2011). Ensino de Sociologia: periodização e campanha pela obrigatoriedade. Cadernos CEDES, 31(85), 359-382. https://doi.org/10.1590/S0101-32622011000300004

Nagle, J. (1976). Educação e sociedade na Primeira República. EPU/MEC.

Oliveira, A. (2013). Revisitando a história do ensino de Sociologia na Educação Básica. Acta Scientiarum. Education, 35(2), 179-189. https://doi.org/10.4025/actascieduc.v35i2.20222

Oliveira, A. (2019). O Ensino de Sociologia no Uruguai: uma análise a partir das narrativas dos professores. Política \& Sociedade, 18(41), 261-279. https://doi.org/gqtb

Oliveira, A. (2020). La enseñanza de las Ciencias Sociales en Brasil hoy. REIDICS: Revista de Investigación en Didáctica de las Ciencias Sociales, 7, 207-222. https://doi.org/10.17398/2531-0968.07.207

Oliveira, A. y Melchioretto, B. (2020). O ensino de sociologia como tema de pesquisa nas ciências sociais brasileiras. Revista Brasileira de Informações Bibliográficas em Ciências Sociais - BIB, 91(1), 1-26. http://anpocs.com/images/BIB/n91/BIB_0009102_05-02_amurabi.pdf

Saviani, D. (2009). Escola e democracia. Autores Associados.

Saviani, D. (2011). História das ideias pedagógicas no Brasil. Editores Associados.

Schwartzman, S., Bomeny, H. M. B. y Costa, V. M. R. (2000). Tempos de Capanema. Edi-tora Paz e Terra e Fundação Getúlio Vargas.

Silva, I. L. F. (2010). O Ensino das Ciências Sociais/Sociologia no Brasil: histórico e pers-pectivas. En A. C. Moares (Coord.), Coleção Explorando o Ensino: Sociologia (1. ${ }^{\mathrm{a}}$ ed., pp. 23-31). MEC.

Sáez-Rosenkranz, I. y Prats Cuevas, J. (2018). Didáctica de las Ciencias Sociales y libros de texto. Didacticae, (4), 2-8. https://doi.org/10.1344/did.2018.4.2-8

Soares, J. da C. (2009). O Ensino de Sociologia no Colégio Pedro II (1925-1941) (Trabajo de máster no publicado). Universidade Federal do Rio de Janeiro, Rio de Janeiro. 
Trindade, H. (2018). "Disciplinarização" e construção institucional da sociologia nos países fundadores e sua reprodução na América Latina. Sociologias, 20(47), 210-256. https://dx.doi.org/10.1590/15174522-020004707

Villas Bôas, G. (2006). Mudança Provocada: passado e presente no pensamento sociológico brasileiro. Editora FGV.

Xavier, L. N. (2002). Para além do campo educacional: um estudo sobre o Manifesto dos pioneiros da educação nova (1932). Edusf. 